Faculty of Vet. Med., AL Baath University, Syria.

\title{
SEROLOGICAL STUDY ON BRUCELLOSIS OF SHEEP IN SOUTH SYRIA
}

(With 5 Tables)

\author{
By \\ S. AL-RHMOON and Y. ALYASINO
}

(Received at 3/4/2010)

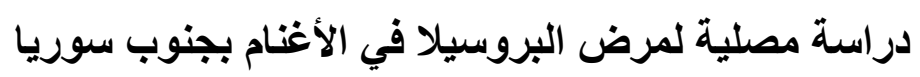

سلطان الرحمون ، باسبين الياسبيو

تم جمع 1115 عينة مصل دم أغنام وذلك بشكل عشو ائي من القطعان المنتشرة في جنوب سورية

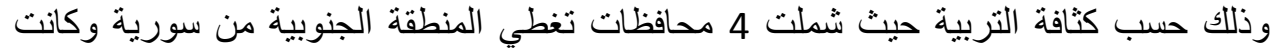

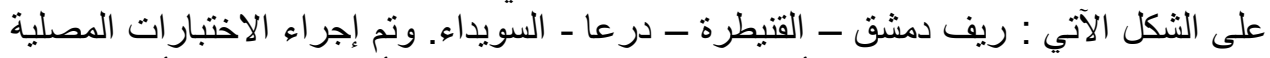

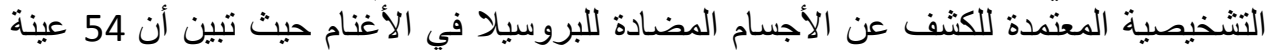

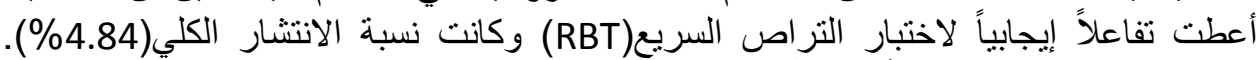

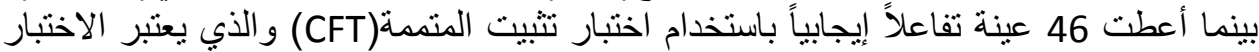

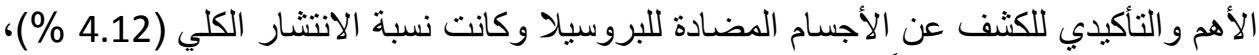

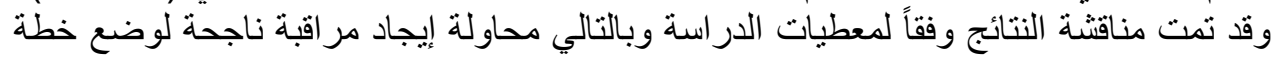
لمكافحة المرض و السيطرة عليه.

\section{SUMMARY}

One thousand one hundred fifteen sheep blood serum samples have been collected arbitrary from the prevailed herds in South Syria and that is according to the breeding density which covered 4 Provinces as following: Damascus, Quoneitra, Daraa and Sueida. Diagnostic serological tests were performed to detect the brucellosis antibodies which showed that 54 samples were positive for Fast agglutination test and the entire prevalence rate was $(4.84 \%)$. Whereas 46 samples were positive for the Complement Fixation Test which is considered the most important test to assure the existence of brucellosis antibodies, and the entire rate was (4.12\%). These results were discussed according to the study data with a trial to find successful monitoring in order to put a plan to control and eradicate this disease.

Key words: مرض البروسيلا ، الأغنام ، اختبار الروزنبغال ، اختبار تثبيت المتمده 


\section{INTRODUCTION المقدمة}

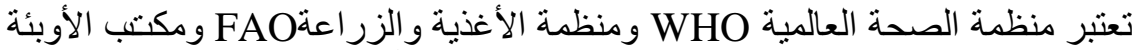

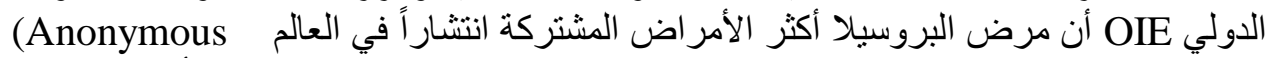
B وينف هذا المرض تحت قائمة مجمو عة الأمر اض اضل 2007; Pappas et al., 2006)

حسب تصنيف مكتب الأوبئة الدولي (OIE, 2000).

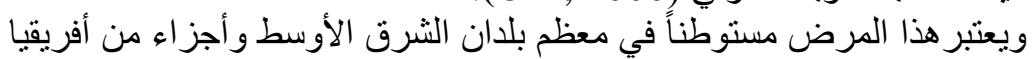

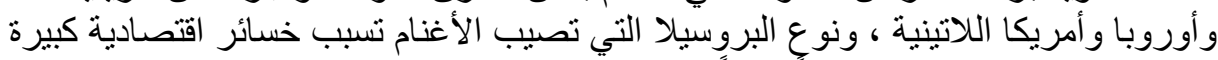
لاى المزار عين كما تشكل خطر أ كبير أ على صحسة الإنسان (Corbel,1997).

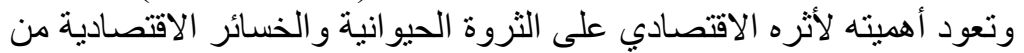

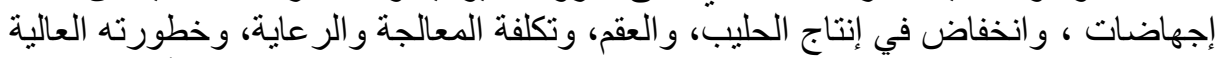

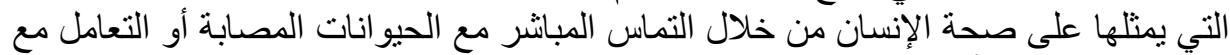

منتجات الحليب و الألبان الملوثة (Garin-Bastuji, et al,. 1998 ; Corbel, 1997).

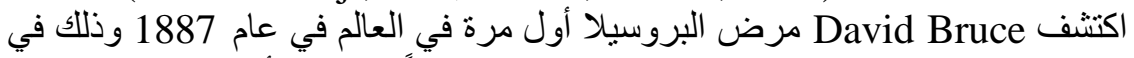

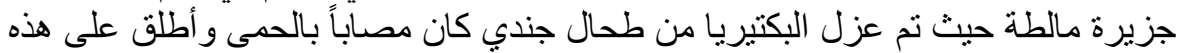

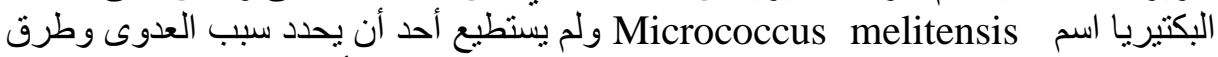
انتقاله حتى عام 1905 حيث شكل بروس فريق بحثه الذي اكتثف أن النيع العدوى تنتقل عند تناول

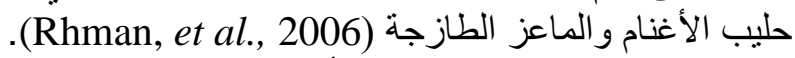
وقد ذكر(Refai أنواع البروسيلا التي تصيب الأغنام و الماعز بشكل رئيسي البئي

و هي البروسيلا المالطية Brucella melitensis ولها ثلاثة أنماط حيوية و البروسيلا

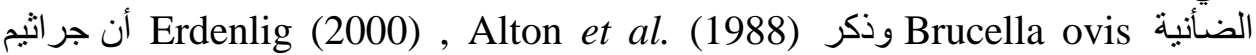

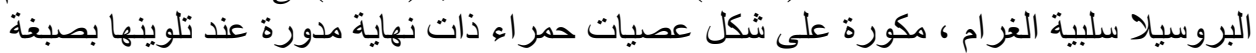

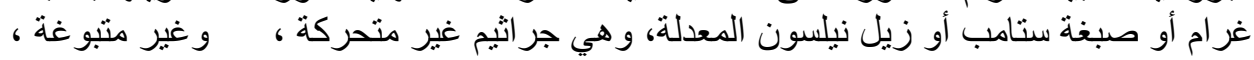

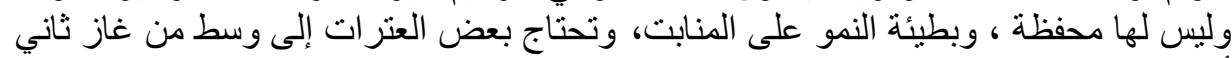

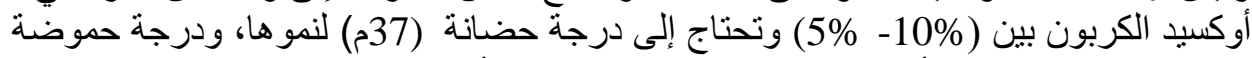

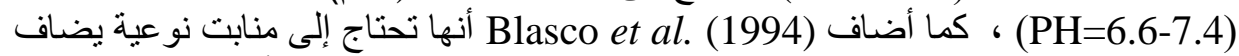

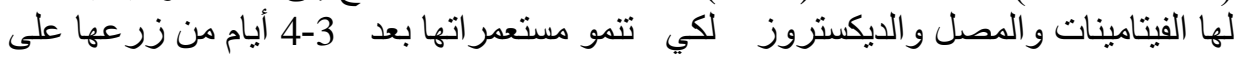

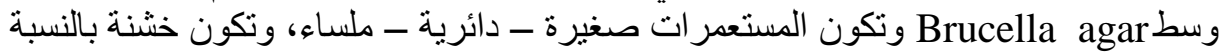

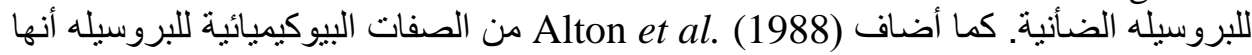

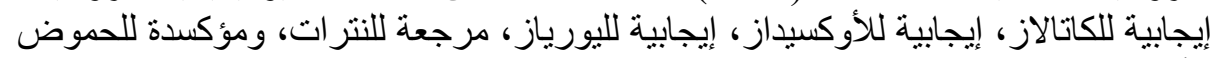

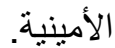

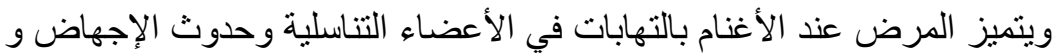

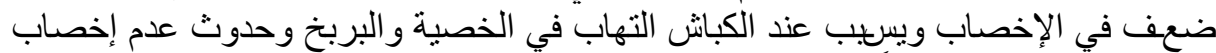

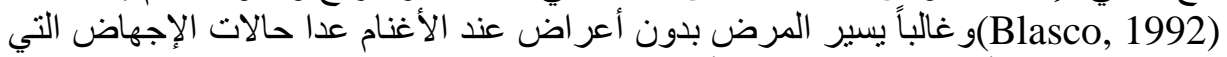

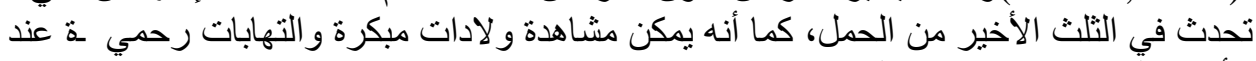

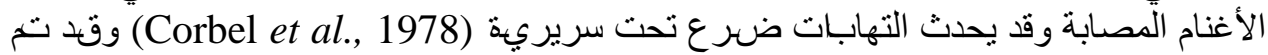

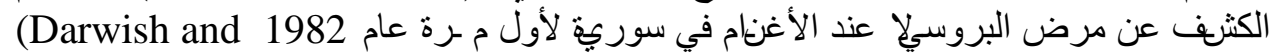

.Ben kiraney, 2001) 
أجريت عدة أبحاث ودر اسات للكثف عن مرض البروسيلا في البر سورية وتحديد نسبة

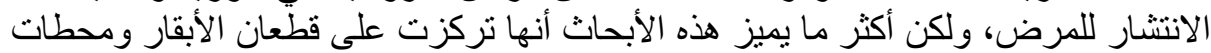

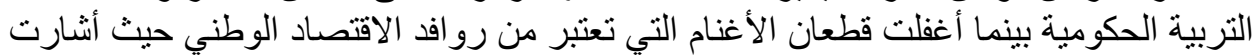

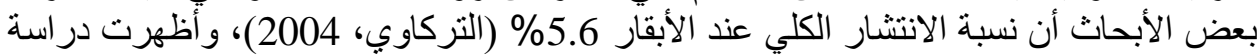
أخرى في سورية أن نسبة انتشار المرض الإي على الأبقار عام 1989 كانت 2.86\% (البشعان

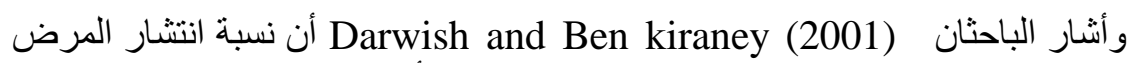

تراوحت بين (2.59-17.48\%) و ذللك حسب نتائج المسح الذي أجرياه عام 1996 في محافظة

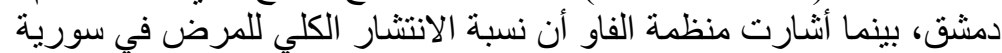

.(FAO,2001)\%5.95

هاف البحث Objectives of the Study:

1 - معرفة مستوى الانتشار المصلي للبروسيلا عند الأغنام في المنطقة الجنوبية من سورية.

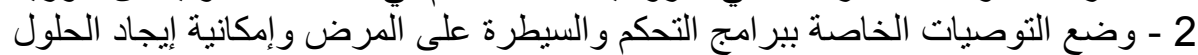
المناسبة.

\section{MATERIALS and METHOD مواد وطرائق البحث}

أجريث هذه الدراسة في المنطقة الجنوبية من سورية حيث شملت أربعة محافظات

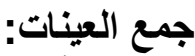
رئيسية تغطي هذا الجز ه من سورية.

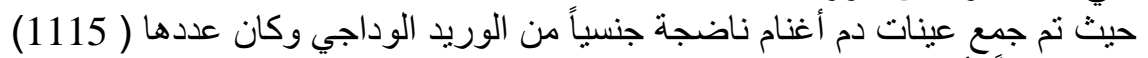

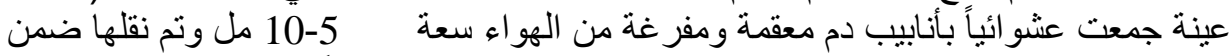

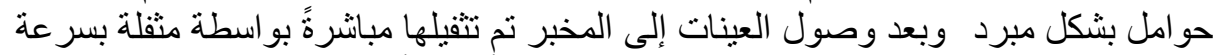

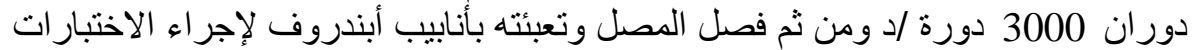

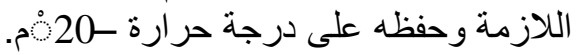

جدول رقم (1): يوضح عدد العينات التي تم جمعها من المحافظات المدروسة

\begin{tabular}{|c|c|c|c|}
\hline المجموع & كباش & نعاج & المحافظة \\
\hline 332 & 15 & 317 & ريف دمشق \\
\hline 232 & 14 & 218 & القنيطرة \\
\hline 229 & 20 & 209 & درعا \\
\hline 322 & 17 & 305 & السويداء \\
\hline
\end{tabular}

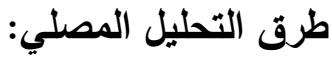


بعد الحصول على المصل وتعبئته في أنابيب أبندروف تم إجر اء أهم الاختبار ات

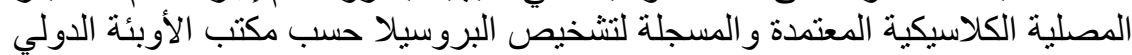

:(OIE,2000)

1 - تفاعل روز البنغال) Rose Bengal) ويستخدم للكثف السريع عن الإصابة في العينة

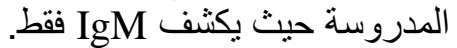

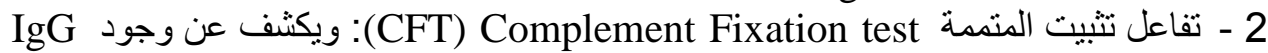

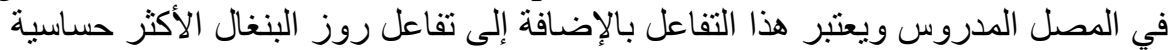

ونو عية بين الاختبارات المصلية الكلاسيكية (1994) . Blasco et al.

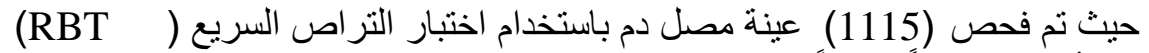

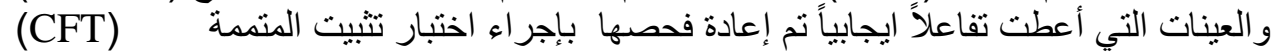

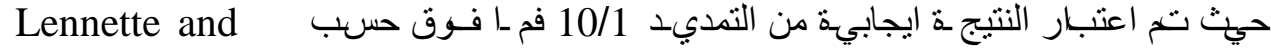
.Alton et al. (1988), Schmidt (1979)

تم إجر اء التحليل الإحصائي لنتائج الدراسة باستخدام اختبار بيرسون مربع كاي

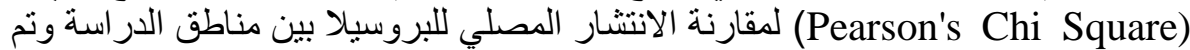
استخدام برنامج التحليل الإحصائي الأمريكي (Analytical Software, 2000) النسخة الثنالثنة.

\section{RESULTS}

\section{النتائج}

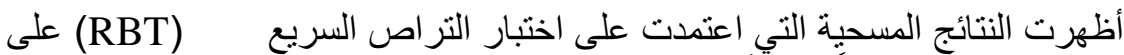

وجود (54) عينة أعطت تفاعلاً إيجابياً من أصل (

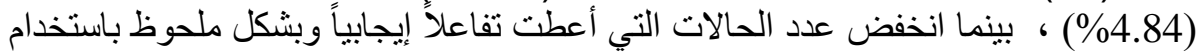

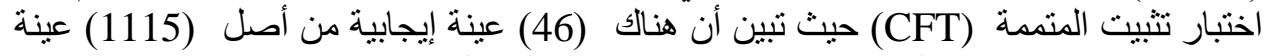
مفحوصة وبنسبة انتشار كلي (CFT) (4.12) كما يتضح في الجدول رقم (2 ) .

جدول (2): نسبة الانتشار المصلي في المحافظات المدروسة بجنوب سوريا اعتماداً على

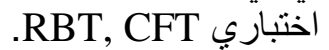

\begin{tabular}{|c|c|c|c|c|c|}
\hline \multicolumn{2}{|c|}{ CFT } & \multicolumn{2}{|r|}{ RBT } & \multirow{2}{*}{ عدد العينات } & \multirow[b]{2}{*}{ المحافظة } \\
\hline نسبة الانتشـار \% & عدد الحالات & الانتشار \% & $\begin{array}{c}\text { عدد الإلحالاتية } \\
\text { الإيجابة }\end{array}$ & & \\
\hline 5.72 & 19 & 6.32 & 21 & 332 & ريف دمشق \\
\hline 2.58 & 6 & 3.87 & 9 & 232 & القنيطرة \\
\hline 4.36 & 10 & 4.80 & 11 & 229 & در عا \\
\hline 3.41 & 11 & 4.03 & 13 & 322 & السويداء \\
\hline 4.12 & 46 & 4.84 & 54 & 1115 & الكلي \\
\hline
\end{tabular}

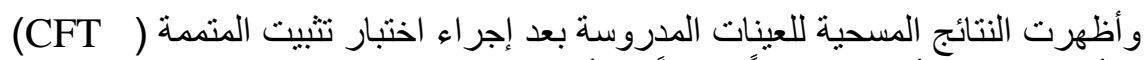

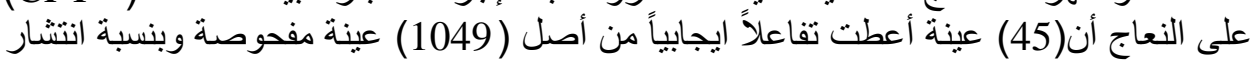


(4.28 \%)، بينما ( 1) عينة واحدة فقط من الكباش أعطت تفاعلاً ايجابياً من أصل ( 66)عينة مفحوصة وبنسبة انتشار (1.51 \% \%) كما يتضح في الجدول رقم (3 ).

جدول (3): نسبة الانتشار المصلي في النعاج و الكباش اعتماداً على اختبار CFT

\begin{tabular}{|c|c|c|c|}
\hline نسبة الانتشار \% & الحالات الايجابية & عدد العينات المفحوصة & الجنس \\
\hline 4.28 & 45 & 1049 & 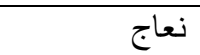 \\
\hline 1.51 & 1 & 66 & كباش \\
\hline 4.12 & 46 & 1115 & المجمو ع الكلى \\
\hline
\end{tabular}

و عند إجر اء اختبار تتبيت المتممة على عينات الأغنام المجهضة تبين أن ( 7)عينات أعطت تفاعلاً ايجابياً من أصل (

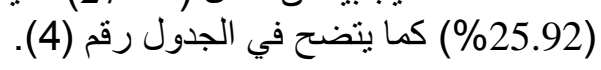

جدول (4): نسبة الانتشار المصلي في النعاج المجهضة وغير المجهضة اعتماداً على اختبار

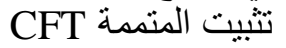

\begin{tabular}{|c|c|c|c|}
\hline نسبة الانتشار \% & الحالات الايجابية & عدد العينات & الإجهاض \\
\hline 25.92 & 7 & 27 & أغنام مجهضة \\
\hline 3.71 & 38 & 1022 & أغنام غير مجهضة \\
\hline 4.28 & 45 & 1049 & المجموع الكلي \\
\hline
\end{tabular}

وتم دراسة حد الثقة 95\% لنسب الانتشار الدصلي والخطأ المعياري بين المحافظات

المدروسة كما يتضح من خلال الجدول رقم (5) التبة

جدول (5): حد الثقة 95 \% لنسبة الانتشار المصلي والخطأ المعباري بين المحافظات المدرسة

\begin{tabular}{|c|c|c|}
\hline الخطأ المعياري & حدود الثقة الأدنى والأعلى & المحافظات و المناطق \\
\hline 0.0101138 & $0.0539-0.0143$ & السويداء \\
\hline 0.0134941 & $0.0700-0.0171$ & درعا \\
\hline 0.0104085 & $0.0462-0.0054$ & القنيطرة \\
\hline 0.0127449 & $0.0821-0.0323$ & ريف دمثق \\
\hline
\end{tabular}

\section{DISCUSSION}


ماز ال مرض البروسيلا من أخطر الأمر اض على صحة الإنسان و التي تسبب خسائر

اقتصادية كبيرة في الأغنام و الماعز والحيو الحيو انات الأخرى (Pappas et al., 2006).

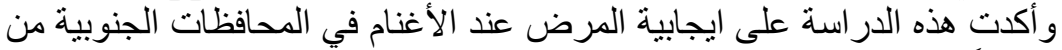

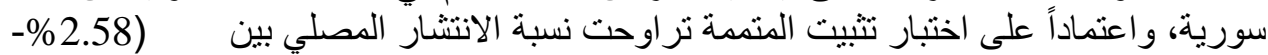

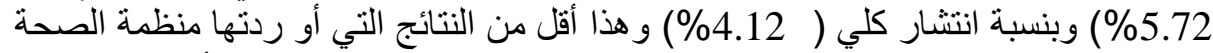

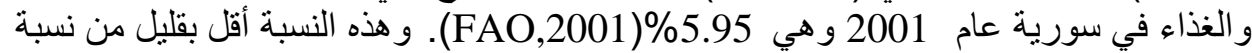
انتشار المرض عند الأغنام في مصر 200 بهي 4.8 (Samaha et al., 2008).

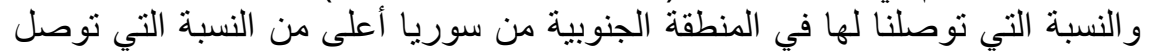

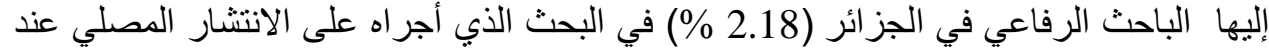

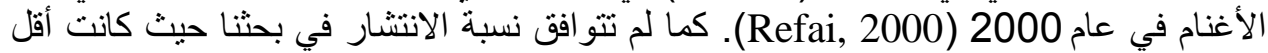
من النسبة التي توصل إليها الباحث مميش (6.5\%) عند الأغنام و(9.7 \% \% البحث الذي أجر اه عام 2001 في المملكة العربية السعودية (2001) (Memish , 2001).

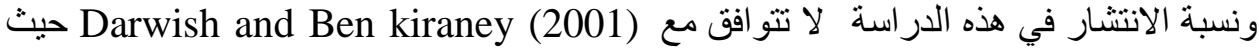

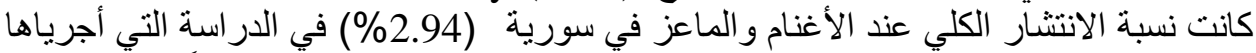

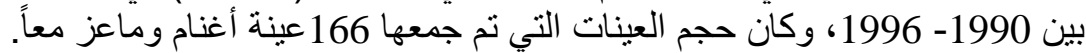

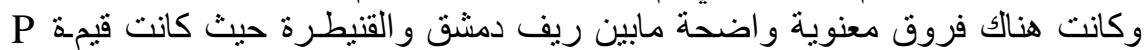

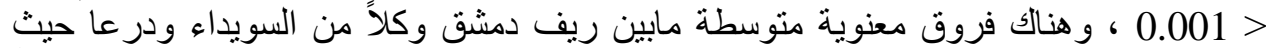

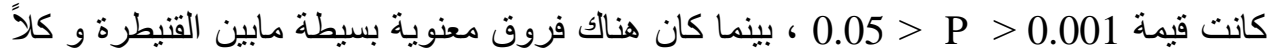

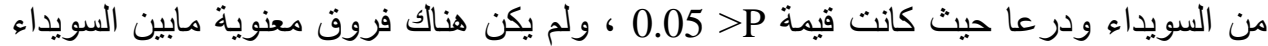

$$
\text { وكانت نسبة الانتشار المصلي عند الإناث }
$$

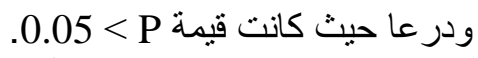

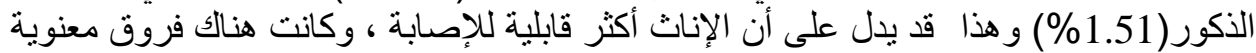

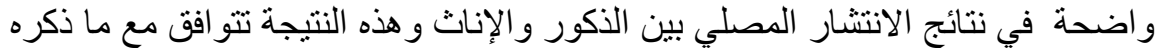
حussein et al. (2005)

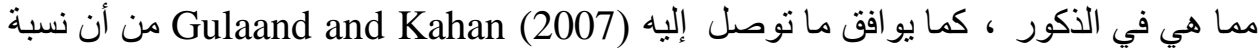

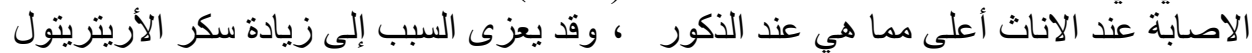

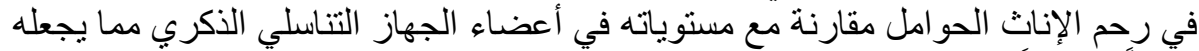

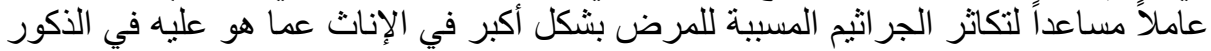
Cadmus, et al. ) (Charanjeet, 2004)

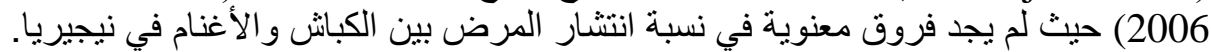

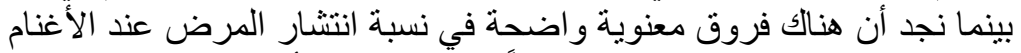

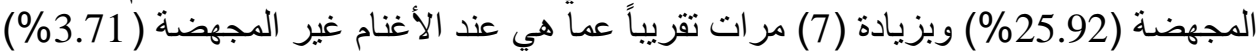

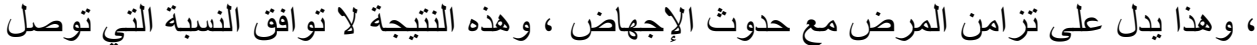

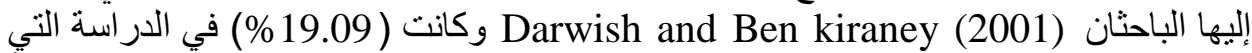
أجرياها بين عامي 1990- 1996 ويعود ذللك أن البحث قد شمل الأغنام و الماعز المجهضة معاً وبنسبة انتشار تراوحت بين (6.25\%-56\%).

\section{CONCLUSIONS} الاستنتاجات 


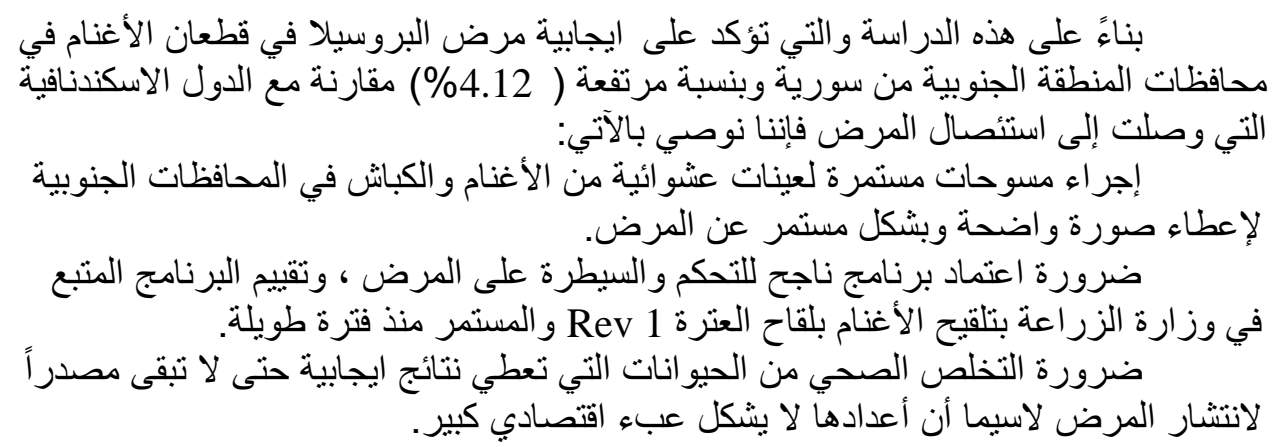

\section{REFERENCES

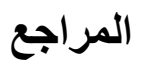

Alton, G.G.; Jones, L.M.; Angus, R.D. and Verger, J.M. (1988): Techniques for brucellosis laboratory. Institute National De La Recherche Agronomique, Paris, pp. 123-130.

Analytical Software (2000): Statistix, Version for windows 4.0, USA.

Anonymous. (2007): FAO, WHO, OIE, Guidelines for a Regional Brucellosis Control Programme for the Middle East.Prepared at the Workshop Of Amman, Jordan 14-17 February 1993, by Drs. Mustafa and Nicoletti, FAO Consultants, Amended at the RoundTable of Maisons-Alfort, France 21-22 September 1995.

Blasco, J.M. (1992): Diagnosis of Brucella melitensis infection small ruminants. In: Prevention of brucellosis in Mediterranean countries, ed. Plommet M, pp. 272-278. Pudoc Scientific, Wage- ningen The Netherlands.

Blasco, J.M.; Garin-Bastuji, B.; M.C.M.; Gerbier, G.; Fanlo, J.; Jimenez De Bagues, M.P. and CAU, C. (1994): Efficacy of different rose Bengal and complement fixation antigens for the diagnosis of brucella melitensis infection in sheep and goats. Vet. Rec., 134: 415-420.

Cadmus, S.I.B.; Ijagbone, I.F.; Oputa, H.E.; Adesokan, H.K. and Stack, J.A. (2006): Serological Survey of Brucellosis in Livestock Animals and Workers In Abadan, Nigeria. African Journal of Biomedical Research; 9: 163-168.

Charanjeet, MS.; Katoch, RC.; Prasenjeet, D.; Rajinider, K. (2004): Application of RBPT, SAT and Avidin - Biotin serum ELISA for detecting brucellosis among livestock in himachal Pradesh. Indian J comp Microbiol Immunol Infect Dis.; 25: 15-18. 
Corbel, M.J.; Gill, K.P.W. and Thomas, E.L. (1978): Methods for the Identification of Brucella. Ministry of Agriculture, Fisheries and Food, UK, ADAS, RCV22.

Corbel, M.J. (1997): Brucellosis: an overview. Emerg Infect Dis.; 3: 213-21.

Darwish, M. and Benkirance, A. (2001): Fild Investigations of Brucellosis in cattle and small ruminants in Syria, 1990-1996, Sci. teah. off. int. Epiz, 20(3), 769-775.

Erdenlig, S. and Sen, A. (2000): Isolation and biotyping of Brucella species in aborted sheep fetuses. Pendik Vet. Microbiol. (31): 31-42.

FAO (Food and Animal Oeganisation) (2001): Syrian report. Directorate of Animal Health, Damascus.

Hussein, AAA.; Sayed ASM. and El Feki, MA. (2005): Seroepidemiological study on human brucellosis in Assiut Governorate. Egypt J. Immumol; 12: 49-56.

Garin-Bastuji, B.; Blasco, J.M.; Grayon, M. and Verger, J.M. (1998): Brucella melitensis infection in sheep: present and future. Vet Res. (29): 255-74.

Gulaand, ST. and Khan, A. (2007): Epidemiology and Epizootology of brucellosis A review. Pakistan Vet. J.; 27(3): 145-151.

Lennette, E.H. and Schmidt, N.J. (1979): Diagnostic procedures for viral and riskettsial infections. 5. Ausgabe, S. 35-42 New York.

Memish, Z. (2001): Brucellosis control in Saudi Arabia: prospects and challenges. J. Chemother., 13: 11-17.33-Anonymous, 1998. WHO Expert Committee on Brucellosis. WHO, Geneva, pp: $1-100$.

OIE (Office International Epizooties) (2000): Manual of standards Diagnostic Tests and Vaccines .Section 2.3, Chapter 2.3.1.

Pappas, G.; Papadimitriou, P.; Akritidis, N.; Christouulm Tsianos EV. (2006): The new global map of human brucellosis. Lancet Infect Dis.(6): 91-9.

Rahman; Juddin, M.; Joon-Seok Chae; Brahman, M. and Islam, M.A. (2006): A short History of Brucellosis: Special Emphasis In Bangladesh Bangl. J. Vet. Med. 4(1): 01-06.

Refai, M. (2002): Incidence and control of brucellosis in the Near East region. Vet Microbiology 90. 81-110.

Samaha, H.; Al-Rowaily, M.; Khoudair, RM. and Ashourhm (2008): Multicenter study of brucellosis in Egypt. Emerg Infect Disease.

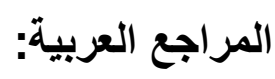


البشعان ، منير (1991): دراسات جرثومية على البروسيلة في الأبقار في سورية. رسالة

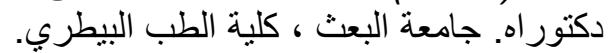

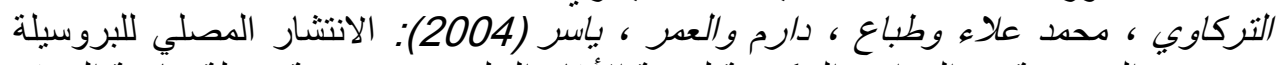

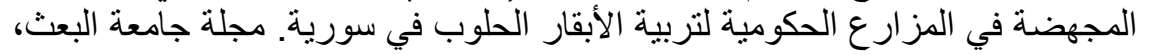

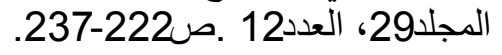

